\title{
Dysregulation within the Prefronto-Parietal Background-Monitoring Network in Schizophrenia
}

\author{
Sarah Wolter ${ }^{1 *}$, Aleksandra Petrovic ${ }^{1}$, Henning Vieker ${ }^{1,2}$, Tobias Melcher ${ }^{1,3}$, Sarah Trost $^{1}$, \\ Esther Kristina Diekhof ${ }^{1,4}$, Anja Richter ${ }^{1,5}$, David Zilles ${ }^{1}$, Oliver Gruber ${ }^{1,5}$ \\ ${ }^{1}$ Department of Psychiatry and Psychotherapy, University Medical Center Göttingen, Göttingen, Germany \\ ${ }^{2}$ Psychiatry and Psychotherapy, University Hospital Hamburg-Eppendorf, Hamburg, Germany \\ ${ }^{3}$ Center of Old Age Psychiatry, Psychiatric University Hospital Basel, Basel, Switzerland \\ ${ }^{4}$ Biocenter Grindel and Zoological Museum, University of Hamburg, Hamburg, Germany \\ ${ }^{5}$ Department of General Psychiatry, Center for Psychosocial Medicine, University of Heidelberg, Heidelberg, \\ Germany \\ Email: "sarah.wolter@med.uni-goettingen.de
}

Received 28 June 2016; accepted 13 August 2016; published 16 August 2016

Copyright (C) 2016 by authors and Scientific Research Publishing Inc.

This work is licensed under the Creative Commons Attribution International License (CC BY).

http://creativecommons.org/licenses/by/4.0/

(c) (7) Open Access

\section{Abstract}

Schizophrenia patients have difficulties in focusing their attention, when distracting information must be ignored. Although it is adaptive in some situations to monitor the background for potentially relevant changes to a certain degree, voluntary attentional processes seem to be more severely disrupted by distracting information in schizophrenia patients compared to healthy controls. Reorienting processes associated with the detection of potentially relevant information outside the current focus of attention have previously shown to activate a bilateral prefronto-parietal network. The aim of the current study was to investigate whether this network is dysregulated in schizophrenia patients using fMRI during the performance in a combined oddball-incongruence task, in which relevant processing must be shielded from distracting irrelevant salient or conflicting information. During the occurrence of both oddballs and incongruence patients exhibited an increased activation of the intraparietal cortex-a saliency sensitive part of the prefronto-parietal network associated with background-monitoring. As this hyperactivation was accompanied by an increased activation in the dopaminergic midbrain, the results of our study link the finding of a hyperactive salience sensitive cortical region to the finding of the hyperdopaminergic state in schizophrenia, supporting the predominant view of psychosis as a

\footnotetext{
${ }^{*}$ Corresponding author.
}

How to cite this paper: Wolter, S., Petrovic, A., Vieker, H., Melcher, T., Trost, S., Diekhof, E.K., Richter, A., Zilles, D. and Gruber, O. (2016) Dysregulation within the Prefronto-Parietal Background-Monitoring Network in Schizophrenia. Journal of Behavioral and Brain Science, 6, 364-376. http://dx.doi.org/10.4236/jbbs.2016.69035 


\title{
state of aberrant salience.
}

\section{Keywords}

\author{
Schizophrenia, Imaging, Attention, Incongruence, Oddball
}

\section{Introduction}

In schizophrenia a wide range of cognitive impairments are well documented, for example attentional deficits e.g., [1]-[8] and an impaired executive control e.g., [9]-[14]. Those deficits become apparent, not only in daily life activities but also in a variety of neuropsychological tests. One of these tests is the Stroop task [15]. In this task, conflict (or "incongruency") between irrelevant color words and the relevant color of the ink creates interference, which manifests in longer reaction times (RTs) and higher error rates compared to the condition of non-conflicting (or "congruent") information dimensions. The so-called Stroop effect has repeatedly been shown to be increased in schizophrenia patients [16] [17].

But what is the neurobiological foundation of that? The neural network associated with incongruency mainly comprises the inferior lateral prefrontal cortex, the intraparietal and inferior parietal cortex, occipito-temporal areas, as well as the posterior medial frontal cortex, including the anterior cingulate cortex (ACC) and the presupplementary motor area (pre-SMA) [18]-[26]. But as a very similar fronto-parietal network has also been found to be associated with the processing of deviant or novel stimuli in "oddball"-paradigms [21] [27] [28], the function of at least parts of this network might not lie in the detection and resolution of behavioral conflicts.

As "oddball" paradigms do not produce an actual response conflict, the fronto-parietal network activated by both Stroop and Oddball tasks is thought to represent a more general cognitive function of a "circuit-breaker", which responds whenever potentially relevant stimuli are detected by a "background-monitoring" system of the brain. Background-monitoring is a mechanism, which enables the organism to rapidly respond to potentially relevant changes outside the current focus of attention. To monitor the environment for potentially significant information is equally important for an organism as the ability to focus on task-relevant information and to ignore task-irrelevant information [29].

In previous studies, a combined oddball-incongruence task was used to directly investigate the neural mechanisms of reorienting processes that are associated with the detection of potentially relevant information outside the current focus of attention. During this paradigm, a cue indicates the relevant stimulus dimension varying in trial-by-trial manner. To perform successfully, top-down attention has to be directed to this stimulus dimension. Beside the task-relevant information each stimulus is also containing task-irrelevant information, whereby task-irrelevant information in some cases violated previously developed expectations either with an evocation of a response conflict or without it. In those trials top-down attentional control is involuntarily interrupted via bottom-up attentional processes and attention has to be redirected to the relevant information again demanding top-down attentional resources. These "circuit breaking" processes seems to rely on acommon bilateral prefrontal-parietal network, comprising the inferior and superior frontal cortex, the intraparietal cortex as well as the medial frontal cortex, independent of whether task-irrelevant information elicited a factual response conflict or not [29]. Furthermore, it could be shown, that this prefrontal-parietal network associated with reorienting processes differs from a predominantly (right-hemispheric) ventral network associated with the detection of factually relevant information outside the current focus of attention [30].

In an adapted version of the combined oddball-incongruence task patients with schizophrenia exhibited specific impairments in both oddball and incongruency trials, which might indicate that a common cognitive process, underlying both task, is disrupted rather than a process specific to either oddballs or incongruency. The shielding of task relevant processing from distracting irrelevant stimulus information is necessary to perform in both tasks and it might therefore be concluded that this process is disrupted in that group of patients [31]. But the question, whether this disruption arises due to the same neural mechanism of a heightened sensitivity of the background-monitoring system (or parts of it) to distracting information, remains to be answered. To directly test the hypothesis of a hypersensitive background-monitoring system in schizophrenia, we compared brain activity during both oddball and incongruency trials between schizophrenia patients and healthy controls using functional magnetic resonance imaging (fMRI). 


\section{Material and Methods}

\subsection{Participants}

20 patients with schizophrenia or schizoaffective disorder and 20 matched healthy controls were included in this study. All patients were recruited from the Department of Psychiatry and Psychotherapy, University Medical Center Goettingen (Germany). Diagnoses were made according to ICD-10 classification standards and were consented within members of the study group and the treating clinical psychiatrist. Additional (semi-)structured interviews were not used to confirm diagnoses. 15 patients were treated with atypical neuroleptics, whereas five patients received a combined medication with typical and atypical neuroleptics. Beside antipsychotics, treatment involved additional anti-depressant medication in eleven cases, benzodiazepine in two cases, anticholinergics in five cases, $\beta$-blockers in three cases and hypnotics in one case. Psychopathology was assessed by the Positive and Negative Syndrome Scale (PANSS), the Montgomery-Asperg Depression Scale (MADRS), and by the Clinical Global Impression (CGI) Scale. The healthy control group was free of any neurological or psychiatric illness. Controls were matched for age, gender and education. All participants had normal or corrected-tonormal vision. Detailed sample characteristics can be seen in Table 1.

All subjects gave informed written consent to the study protocol, which was in accordance with the Declaration of Helsinki and had been approved by the ethics committee of the University Medical Center Goettingen.

Table 1. Demographical and clinical variables including medication and psychopathological scales.

\begin{tabular}{|c|c|c|c|c|c|}
\hline & & & Schizophrenia & Controls & $p$ value $^{\mathrm{b}}$ \\
\hline \multicolumn{3}{|c|}{ Sample size } & 20 & 20 & \\
\hline \multicolumn{3}{|c|}{ Gender (\% female) } & 15.00 & 15.00 & 1.00 \\
\hline \multicolumn{3}{|c|}{ Age at time of testing (years) } & 30.60 & 30.70 & 0.97 \\
\hline \multicolumn{3}{|c|}{ Educational level $^{\mathrm{a}}$} & 4.15 & 4.35 & 0.57 \\
\hline \multicolumn{3}{|c|}{ Age at disease onset (years) } & 26.45 & & \\
\hline \multicolumn{3}{|c|}{ Disease duration (years) } & 4.50 & & \\
\hline \multicolumn{3}{|c|}{ PANSS total } & 53.25 & & \\
\hline \multicolumn{3}{|c|}{ PANSS positive } & 11.75 & & \\
\hline \multicolumn{3}{|c|}{ PANSS negative } & 13.00 & & \\
\hline \multicolumn{3}{|c|}{ MADRS } & 11.90 & & \\
\hline \multicolumn{3}{|c|}{ CGI } & 4.20 & & \\
\hline \multirow{11}{*}{$\begin{array}{l}\text { Medication } \\
\text { (absolute } \\
\text { frequency) }\end{array}$} & \multirow{3}{*}{ Neuroleptics } & Atypical & 15 & & \\
\hline & & Atypical and typical & 5 & & \\
\hline & & Tricyclics & 1 & & \\
\hline & \multirow{3}{*}{ Anti-depressants } & Tetracyclics & 2 & & \\
\hline & & SSRI & 4 & & \\
\hline & & SSNRI & 4 & & \\
\hline & \multicolumn{2}{|c|}{ Benzodiazepine } & 2 & & \\
\hline & \multicolumn{2}{|c|}{ Anticholinergics (e.g. Akineton) } & 5 & & \\
\hline & \multicolumn{2}{|c|}{$\beta$-blockers } & 3 & & \\
\hline & \multicolumn{2}{|c|}{ Hypnotics } & 1 & & \\
\hline & \multicolumn{2}{|c|}{ CPZ-equivalent total daily dosis (mg) } & 842.80 & & \\
\hline
\end{tabular}

Abbreviations: CGI, Clinical Global Impression Scale; MADRS, Montgomery-Asperg Depression Scale; PANSS, Positive and Negative Syndrome Scale; SSNRI, Selective Serotonin-Norepinephrine Reuptake Inhibitors; SSRI, Selective Serotonin Reuptake Inhibitor. ${ }^{\mathrm{a}}$ Education was defined by a five-point scale with 1 corresponding to no school graduation and 5 corresponding to school graduation qualifying for university entrance. ${ }^{b} P$ value for group difference determined by an independent samples t-test (two-sided). 


\subsection{Experimental Protocol}

Subjects underwent fMRI while performing a cued task-switching paradigm (see Figure 1), in which they had to classify a geometric object according to one of the stimulus varying stimulus dimensions-either color (color task) or shape (shape task). The relevant dimension could vary in a trial-by-trial manner and was indicated by a word cue. Two shapes and two colors were each assigned to different responses-one to the press of the left button with the index finger of the right hand and the other to the press of the right button with the middle finger of the right hand. So the relevant and irrelevant dimension could both refer to the same response (congruent stimuli) or to different responses (incongruent stimuli). Additionally, in the shape task, at rare occasions there was a third color without a response assignment (neutral stimuli). Occurring relatively rare among the other stimuli (congruent and incongruent), neutral stimuli represented an "oddball".

Each trial started with a cue, presented for $500 \mathrm{~ms}$. The subsequent target was delivered after a constant cuetarget interval of $250 \mathrm{~ms}$ and was presented for $1000 \mathrm{~ms}$ followed by the next cue after a constant target-cue interval of $250 \mathrm{~ms}$. Responses were registered until the end of this interval. The total trial length was $2000 \mathrm{~ms}$.

The experiment comprised a total of 240 trials. 105 trials were congruent, 105 trials were incongruent and 30 trials were oddball trials. Excluding oddball trials, color and shape tasks were presented equally often. To allow for analyzing the data in an event-related fashion, trials were presented in a pseudorandomized order.

\section{3. fMRI Measurement}

Using an eight-channel head coil, the experiment was carried out on a 3T Siemens TRIO MRI scanner (Magnetom Siemens Trio, Erlangen). For coregistration of the functional data a structural T1-weighted MRI was acquired (field of view: $256 \mathrm{~mm}$, TE: $3.26 \mathrm{~ms}$, TR: $2250 \mathrm{~ms}$, flip angle: $9^{\circ}$, voxel size: $1 \times 1 \times 1 \mathrm{~mm}^{3}$ ). During functional imaging 33 axial slices parallel to the anterior commissure-posterior commissure line were obtained in ascending acquisition order (voxel size: $3 \times 3 \times 3 \mathrm{~mm}^{3}$, interslice gap: 20\%) using a gradient-echo echoplanar imaging (EPI) sequence (field of view: $256 \mathrm{~mm}$, matrix size: $64 \times 64$, TE: $30 \mathrm{~ms}$, TR $=2000 \mathrm{~ms}$, flip angle: $70^{\circ}$ ). A total of 251 volumes was acquired.

Stimuli were presented to the subjects via MR-compatible LCD goggles. The head was stabilized by small

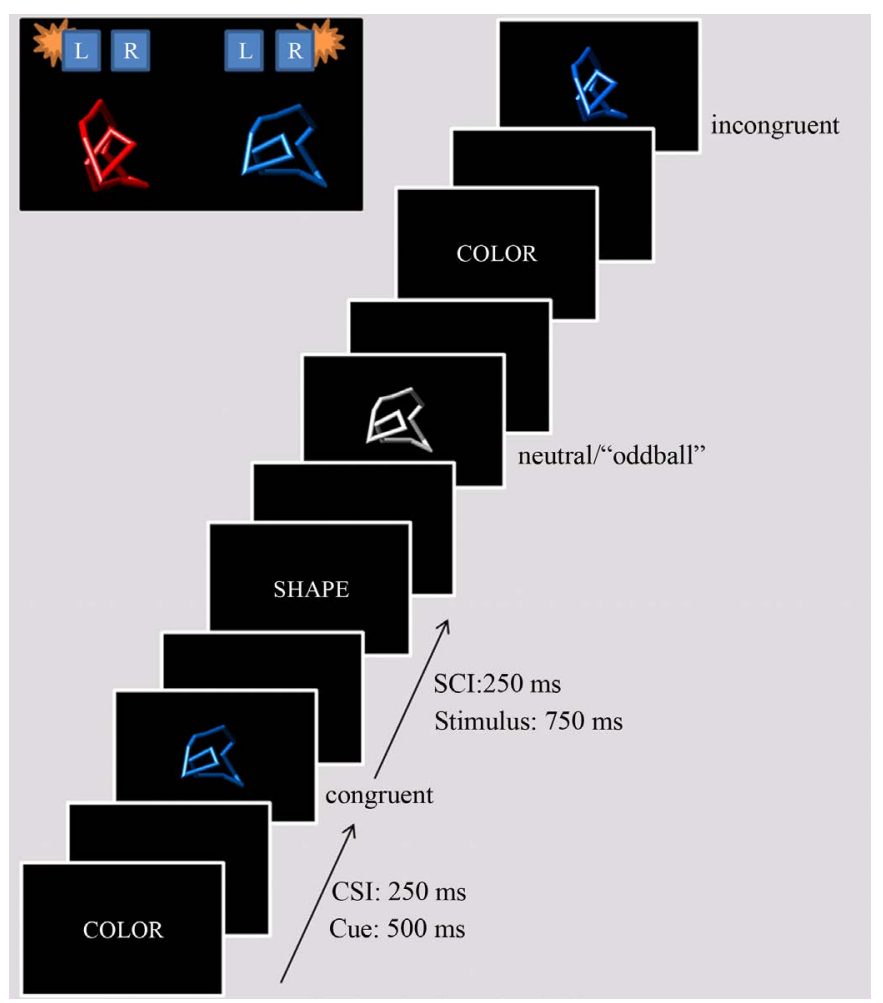

Figure 1. Example of the experimental trial sequence. 
cushions to avoid head movements during scanning. Triggering of the visual stimulation by the scanner impulse during the functional data acquisition and generation of stimuli was conducted using Presentation Software (Neurobehavioral Systems, Albany, USA).

\section{4. fMRI Data Analysis}

The functional images were preprocessed and statistically analyzed using SPM5 (Wellcome Department of Imaging Neuroscience, London, UK). Preprocessing comprised realignment and unwarping, correction for slicetime acquisition differences (reference slice: 1) and low frequency fluctuations, coregistration, normalization into standard stereotactic space (to the Montreal Neurological Institute (MNI) skull-stripped structural template), and spatial smoothing with a Gaussian kernel (FWHM $=9 \mathrm{~mm}$ ).

For the statistical analysis of the functional images, the onsets of all experimental conditions were modelled as separate regressors by the convolution with a hemodynamic response function accounting for the delay of the BOLD (blood oxygen level-dependent) response. For each subject, statistical images were computed repressenting the contrasts oddball condition (shape task) minus implicit baseline, and incongruent condition (shape task) minus implicit baseline. These first-level images were included in random effect analyses conducting onesample t-tests of each group separately, and in a two-sample t-test for group comparison. Search criterion for statistical effects was set at $\mathrm{p}<0.005$ (uncorrected). To correct for multiple testing, we used FDR-correction at a significance level of $\mathrm{p}<0.05$. In between-group comparisons for brain regions with a priori hypotheses-due to previous replicated findings-we used FWE-correction for small-volume (6 $\mathrm{mm}$ sphere) around coordinates from Gruber et al. (2009) at a significance level of $\mathrm{p}<0.05$.

\section{Results}

\subsection{Oddball Contrast}

In the oddball contrast, whole brain analysis of the functional neuroimaging data showed reliable activation of a bilateral cortical network both in the group of healthy subjects and in the patient group (see Table 2). This network included regions previously found to be involved in this task, like the inferior frontal junction (IFJ), the posterior frontomedial cortex (pFMC), the posterior superior frontal cortex (pSFC) and the intraparietal cortex [30] [32]. Furthermore, in both groups oddballs were accompanied by an increased activation of the bilateral extrastriatal visual cortex, frontal insular-opercular cortex, inferior parietal lobule as well as precentral gyrus and by an elevated activation of the right ACC.

As opposed to this, activations of the dopaminergic midbrain/ventral tegmental area (VTA) were only present in the patient group but not in healthy subjects. All other activations were present in both groups.

A two-sample t-test for group comparison revealed that, consistent with our prior hypothesis, schizophrenic patients showed significantly higher brain activation in the bilateral intraparietal cortex. Matching the finding of midbrain/VTA activations limited to the patient group, group comparisons showed a hyperactivation of the midbrain/VTA.

\subsection{Incongruency Contrast}

In the incongruency contrast, whole brain analysis revealed a similar set of activated regions that were already found in the oddball contrast (see Table 3). Some additional loci of activation were found in the inferior frontal sulcus (IFS), the middle temporal gyrus (MTG) and the intra-occipital sulcus for healthy subjects as well as for schizophrenic patients.

In this contrast again, the two-sample t-test for group comparison revealed the intraparietal cortex to be hyperactivated in the patient group compared to healthy control subjects (see Figure 2(a)). Further hyperactivations in the patient group were found in the following areas: left inferior parietal lobule, right MTG and left intra-occipital sulcus. Subtle hyperactivations at the significance level of $p<0.05$ (uncorrected) were found in the dopaminergic midbrain/VTA (see Figure 2(b)), the right frontal eye field (FEF), left IFS and the left posterior frontomedial cortex (pFMC) extending to the pre-SMA.

\subsection{Correlations with Psychopathology and Behavioral Effects}

Those regions of the brain, for which we found activation differences between schizophrenia patients and healthy 
Table 2. Brain regions activated by the color oddball.

\begin{tabular}{|c|c|c|c|}
\hline \multirow{2}{*}{ Region } & Schizophrenic patients & Healthy controls & $\begin{array}{c}\text { Schizophrenic } \\
\text { patients }>\text { healthy controls }\end{array}$ \\
\hline & $\begin{array}{l}\text { MNI coordinates } \\
\text { (t-values) }\end{array}$ & $\begin{array}{l}\text { MNI coordinates } \\
\text { (t-values) }\end{array}$ & $\begin{array}{l}\text { MNI coordinates } \\
\text { (t-values) }\end{array}$ \\
\hline \multicolumn{4}{|l|}{ A priori regions of interest } \\
\hline L IFJ & $-42-336(3.00)$ & $-39030(4.67)$ & n.s. \\
\hline R IFJ & [39 921 (2.77)] & 42327 (3.45) & n.s. \\
\hline $\mathrm{L}$ intraparietal cortex & $-27-6042(5.15)$ & $-27-5151(5.11)$ & $-33-6945(2.90)^{*}$ \\
\hline $\mathrm{R}$ intraparietal cortex & $30-6042(7.47)$ & $30-4545(5.90)$ & $30-6642(2.88)^{*}$ \\
\hline L pFMC/pre-SMA & $-61251(5.49)$ & $-6657(5.87)$ & n.s. \\
\hline R pFMC/pre-SMA & 6957 (4.67) & 12654 (4.27) & n.s. \\
\hline L pSFC/FEF & $-36-360(4.31)$ & $-21-660(5.00)$ & n.s. \\
\hline $\mathrm{R}$ pSFC/FEF & $24-354(4.61)$ & 33051 (3.34) & n.s. \\
\hline L midbrain/VTA & $-6-24-15(4.12)$ & n.s. $\left(\mathrm{p}_{\text {uncorr }}>0.1\right)$ & $-12-27-21(2.88)^{+}$ \\
\hline L inferior parietal lobule & $-54-3057(5.67)$ & $-42-3948(5.20)$ & $-57-3654(2.90)^{+}$ \\
\hline $\mathrm{R}$ inferior parietal lobule & $30-2739$ (4.79) & $30-2433(5.05)$ & n.s. \\
\hline L precentral gyrus & $-48-354(2.70)$ & $-48-354(3.87)$ & n.s. \\
\hline $\mathrm{R}$ precentral gyrus & $45636(2.61)^{+}$ & 45348 (4.06) & n.s. \\
\hline L frontoopercular cortex/insular cortex & {$[-30243(2.38)]$} & $-242415(4.00)$ & n.s. \\
\hline R frontoopercular cortex/insular cortex & 39339 (3.97) & $36213(2.54)^{++}$ & n.s. \\
\hline R ACC & 121839 (4.23) & $151833(2.80)^{+}$ & n.s. \\
\hline L extrastriate visual cortex & $-30-939(7.08)$ & $-30-879(7.91)$ & n.s. \\
\hline R extrastriate visual cortex & $33-54-18(12.17)$ & $30-9312(13.04)$ & n.s. \\
\hline
\end{tabular}

Abbreviations: ACC, anterior cingulate cortex; FEF, frontal eye field; IFJ, inferior frontal junction; L, left; n.s., not significant; pFMC, posterior frontomedial cortex; pSFC, posterior superior frontal cortex; R, right; SMA, supplementary motor area; VTA, ventral tegmental area. If not indicated differentially, effects on regional brain activation were significant at a level of $\mathrm{p}<0.05$, FDR-corrected for the entire brain. ${ }^{*} \mathrm{p}<0.05$, FWE-corrected for small volume ( $6 \mathrm{~mm}$ sphere) around a priori coordinates from Gruber et al. (2009); ${ }^{+} \mathrm{p}<0.005$, uncorrected. For purposes of completeness and better understanding, subthreshold effects ( $\mathrm{p}<0.05$, uncorrected) are reported using square brackets.
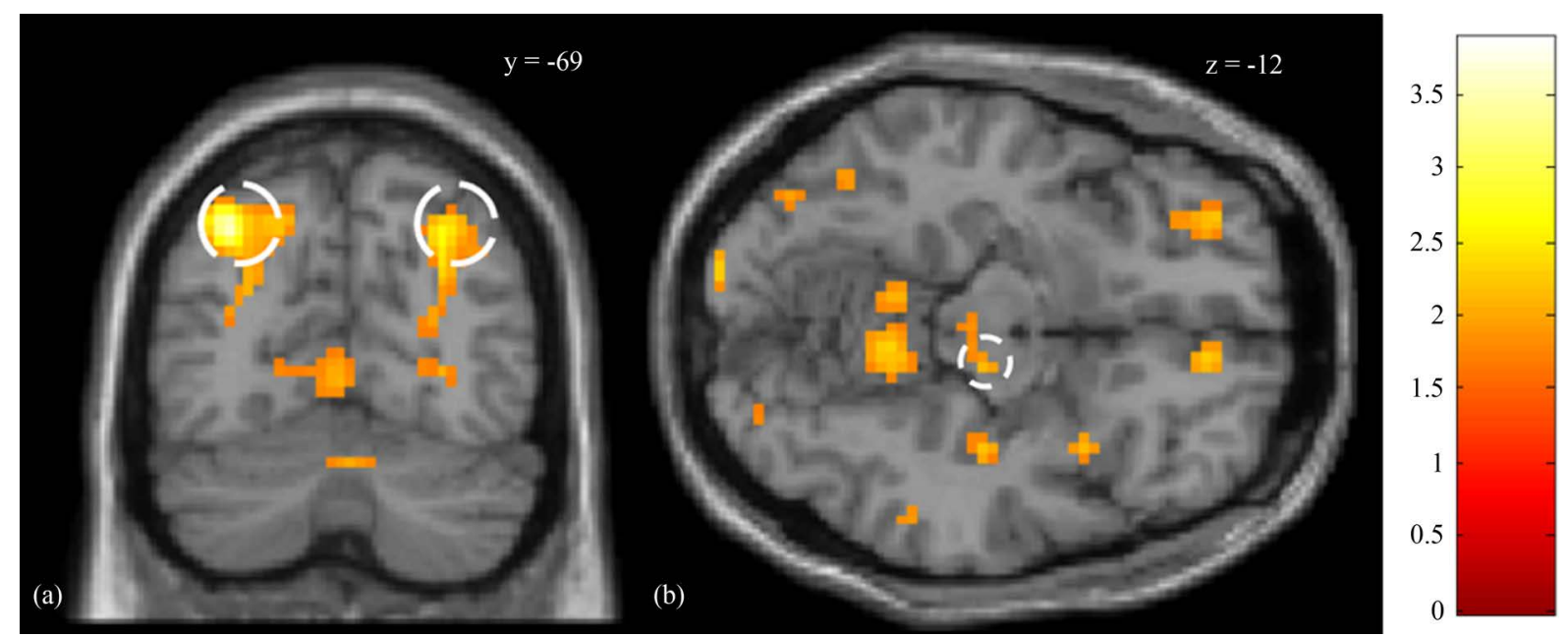

Figure 2. Increased incongruency effect on the activation of (a) the intraparietal cortex and (b) the dopaminergic midbrain/ VTA (schizophrenia patients $>$ healthy controls; $\mathrm{p}<0.05$, uncorrected). 
Table 3. Brain activations evoked by response conflicts.

\begin{tabular}{|c|c|c|c|}
\hline \multirow{2}{*}{ Region } & Schizophrenic patients & Healthy controls & $\begin{array}{c}\text { Schizophrenic patients > } \\
\text { healthy controls }\end{array}$ \\
\hline & $\begin{array}{l}\text { MNI coordinates } \\
\text { (t-values) }\end{array}$ & $\begin{array}{l}\text { MNI coordinates } \\
\text { (t-values) }\end{array}$ & $\begin{array}{l}\text { MNI coordinates } \\
\text { (t-values) }\end{array}$ \\
\hline \multicolumn{4}{|l|}{ A priori regions of interest } \\
\hline L IFJ & $-51639(4.14)$ & $-42033(4.25)$ & n.s. \\
\hline R IFJ & 45330 (5.36) & 45333 (3.63) & n.s. \\
\hline L intraparietal cortex & $-27-5751(7.02)$ & $-27-4851(4.62)$ & $-33-6945(3.48)^{*}$ \\
\hline $\mathrm{R}$ intraparietal cortex & $33-5451(9.54)$ & $27-5148(5.53)$ & $30-6642(2.98)^{*}$ \\
\hline L pFMC/pre-SMA & $-31551(7.31)$ & $-9657(5.14)$ & [-6 $2142(2.35)]$ \\
\hline R pFMC/pre-SMA & $61254(6.08)$ & 12954 (3.88) & n.s. \\
\hline $\mathrm{L}$ pSFC/FEF & $-33-669(4.79)$ & $-30-657(4.71)$ & n.s. \\
\hline $\mathrm{R}$ pSFC/FEF & $24-354(6.53)$ & 33051 (3.96) & {$[24-354(2.38)]$} \\
\hline L midbrain/VTA & $3-27-18(6.13)$ & {$[0-33-24(1.94)]$} & {$[12-21-12(2.12)]$} \\
\hline L inferior parietal lobule & $-39-4854(6.69)$ & $-45-3651(6.62)$ & $-57-3651(2.99)^{+}$ \\
\hline $\mathrm{R}$ inferior parietal lobule & $42-3342(5.38)$ & $39-3336(4.17)$ & n.s. \\
\hline $\mathrm{L}$ precentral gyrus & $-27-357(5.10)$ & $-30-657(4.71)$ & n.s. \\
\hline $\mathrm{R}$ precentral gyrus & 48345 (3.59) & 54051 (4.09) & n.s. \\
\hline L IFS & $-332127(3.43)$ & n.s. & {$[-361536(2.29)]$} \\
\hline L frontoopercular cortex/insular cortex & $-30243(3.88)$ & -30249 (3.37) & n.s. \\
\hline $\mathrm{R}$ frontoopercular cortex/insular cortex & $331815(6.56)$ & 302412 (3.55) & n.s. \\
\hline R ACC & $121839(4.74)$ & $182127(4.10)$ & n.s. \\
\hline R MTG & $42-483(4.55)$ & $45-54-3(3.46)^{+}$ & $42-519(3.88)^{+}$ \\
\hline L extrastriate visual cortex & $-24-969(8.42)$ & $-30-876(8.43)$ & n.s. \\
\hline R extrastriate visual cortex & $30-9012(9.78)$ & $30-909(10.63)$ & n.s. \\
\hline L intra-occipital sulcus & $-27-8121(7.40)$ & {$[-27-8121(2.84)]$} & $-30-7821(3.10)^{+}$ \\
\hline $\mathrm{R}$ intra-occipital sulcus & $30-9018(8.91)$ & $30-9018(6.43)$ & n.s. \\
\hline
\end{tabular}

Abbreviations: ACC, anterior cingulate cortex; FEF, frontal eye field; IFJ, inferior frontal junction; IFS, inferior frontal sulcus; L, left; MTG, middle temporal gyrus; n.s., not significant; pFMC, posterior frontomedial cortex; pSFC, posterior superior frontal cortex; R, right; SMA, supplementary motor area; VTA, ventral tegmental area. If not indicated differentially, effects on regional brain activation were significant at a level of $\mathrm{p}<0.05$, FDR-corrected for the entire brain. ${ }^{*} \mathrm{p}<0.05$, FWE-corrected for small volume (6 mm sphere) around a priori coordinates from Gruber et al. (2009); ${ }^{+} \mathrm{p}<0.005$, uncorrected. For purposes of completeness and better understanding, subthreshold effects ( $p<0.05$, uncorrected) are reported using square brackets.

controls, were included in correlational analyses. For this purpose, mean $\beta$ values from ROIs (5 mm sphere) around significant coordinates from the t-contrasts of the group-comparison were extracted using MarsBaR-Marseille ROI toolbox, version 0.43 [33]. Correlations were calculated between mean $\beta$ values and PANSS positive and negative for schizophrenia patients; and between mean $\beta$ values and behavioral effects (incongruency effect on RT, incongruency effect on error rate, oddball effect on RT, oddball effect on error rate) for all subjects. After correction for multiple comparisons no correlation reached significance level.

\section{Discussion}

The goal of this study was to investigate neurofunctional changes of schizophrenia patients in situations, in which task relevant processing must be shielded from distracting irrelevant stimulus information, both in conflicting situations and in situations with an irrelevant oddball. For this purpose, we directly compared the effect 
of salient and conflicting information on brain activation between schizophrenic patients and healthy controls using functional MRI.

FMRI analysis of oddball and incongruency effects on brain activation revealed that both experimental conditions were associated with activation of a common fronto-parietal network comprising inferior and superior frontal cortices, intraparietal cortices, as well as medial frontal cortices.

Consistent with our prior hypothesis, group comparisons revealed that distraction by salient and by conflicting information was associated with abnormal activations within a fronto-parietal network, which was previously found to be associated with background monitoring of the environment for potentially relevant events outside the current focus of attention [29] [30]. In schizophrenia patients abnormal activation within this network in terms of a hyperactivation concerned the intraparietal cortex. Evoked by response conflicts, additional hyperactivations of frontal, temporal as well as occipital regions were found. Surprisingly, abnormally elevated activations were also found in the dopaminergic midbrain/VTA, both in the oddball and in the incongruency contrast. Particularly in the situation of distracting "oddballs" the differential activation of the dopaminergic midbrain/ VTA seemed to be of qualitative rather than quantitative nature, since dopaminergic midbrain/VTA activations were totally absent in healthy controls.

The detection of a fronto-parietal network activated by both tasks in healthy controls as well as in schizophrenia patients conforms to both prior findings of our group [29] [30] [32] and to findings of other groups using response conflict [18]-[26] and oddball paradigms [21] [27] [28]. While some of the activated regions of that network might represent executive control processes, involved in the redirection of attention to task-relevant information, others might serve as a "circuit breaker" of top-down attentional control processes, which allow potentially significant events to catch attention. Although both the FEF and the intraparietal cortex are assumed to be involved in the control of voluntary attention in humans [34]-[37], the intraparietal cortex was also shown to be sensitive to bottom-up attentional influences that are driven by the perceptual salience of task-irrelevant changes [38].

In a previous behavioral study, schizophrenic patients showed a deficit in the shielding of task relevant processing from distracting irrelevant stimulus information, both in conflicting situations and in situations with an irrelevant oddball [31]. The underlying pathophysiological mechanisms of that deficit have not been directly investigated so far, although there are several studies using oddballs [39]-[45] and conflicts in the investigation of neurofunctional changes in schizophrenia [46]-[51]. None of them reported dysfunctional activation of the VTA, which was found to be hyperactivated in the patient group of our study. Only a few of them describe abnormal activations of the intraparietal cortex. Instead findings of those studies mainly concerned the anterior and posterior cingulate cortices as well as the dorsolateral and ventrolateral prefrontal cortices, regions that are primarily related to the detection of deviant and conflicting information and to the resolution of conflicts, respectively.

The hyperactivation of the intraparietal cortex, found in the present study, does not correspond to results obtained by typical oddball and Stroop tasks. This might be owed to the special characteristics of our paradigm. Critically, our task differs from those used by the other studies in several ways: Firstly, an oddball stimulus in our study comprises both a relevant and an irrelevant dimension, whereas the oddball stimulus was either relevant or irrelevant in the other studies. Thus, in our study attending the oddball directly interrupts the task performance, just as attending to incongruent information does. Accordingly, the presence of interrupting information is characteristic for both critical conditions of our paradigm. In both conditions attention might be involuntarily caught by the irrelevant but salient stimulus dimension and must be redirected to the task-processes that were previously found to involve intraparietal cortices [19] [24] [26]. A second specific feature of our task design that differs from previous studies is the change of the relevant dimension in the course of the experimental session. In contrast, in other studies using the traditional Stroop task the ink color generally is the only relevant dimension. Consequently, in our task, subjects might be more distractible by the irrelevant dimension per se, as it is necessary to adaptively change the focus of attention. As this holds true for both oddball and incongruent trials, cognitive processes involved during both trials might be quite similar.

A lesion of the parietal cortex leads to severe attentional dysfunctions which are termed neglect syndrome. Patients with schizophrenia display deficits in visuomotor control and visual attention qualitatively similar to those observed in the neglect syndrome [52]. From this perspective our finding of a hyperactivated intraparietal network is not surprising, as one could expect that both pathological conditions also share a parietal dysfunction. Patients with neglect syndrome show the prominent deficit in paying attention to the contralesional hemifield. Consequently, neglect patients eat only one side of the meal on a plate, wash and shave themselves only on one 
half of the body, and have many other problems in daily life activities requiring spatial attention. Neuropsychological testing with detection and discrimination tasks revealed that neglect patients are capable to detect a stimulus on the contralesional side unless the contralesional stimulus is presented simultaneously with an ipsilesional stimulus at a symmetric position [53]. The neglecting of contralesional stimuli in the presence of competing stimuli was previously found to rely on the middle third of the right intraparietal sulcus (IPS) [54]. Furthermore, this region is hypothesized to be involved in the compilation of a saliency map. In this map stimuli or stimulus features with varying relative attentional weight are calibrated [55].

The FEF was shown to be often co-activated with the intraparietal sulcus [55]. Furthermore, in a monkey study, distracter stimuli produced larger responses in FEF neurons when they have previously served as targets [56]. As the target dimension in our task changes from trial to trial, this might explain that in the present study the hyperactivation of the intraparietal cortex was accompanied by an increased activation of the FEF in the condition of incongruent stimulus dimensions.

Hyperactivations of the VTA could not be expected on the basis of results obtained by previous studies using the combined oddball-task-switching paradigm. On the other hand, this finding matches with the dopamine hypothesis of schizophrenia pathophysiology.

Dysregulation of the dopaminergic system is one of the pathophysiological key findings in schizophrenia. Initially, an overall hyperdopaminergic state was assumed to account for the psychotic symptoms of the disorder [57]. But, due to the finding of a reduced dopamine release in prefrontal cortices, the dopamine hypothesis of schizophrenia was modulated in terms of describing the aberrant state of the dopamine system in schizophrenia as striatal hyperdopaminergic and prefrontal hypodopaminergic [58].

Dopamine plays a central role in the mesolimbic "reward system" of the brain. It is synthesized in the neurons of the ventral tegmental area, a midbrain area with plenty projections to subcortical (nucleus accumbens) and cortical (prefrontal cortex) target regions [59] [60].

Current versions of the dopamine hypothesis of schizophrenia focus on the role of the dysregulated dopaminergic system in the aberrant assignment of salience to irrelevant stimuli [61] [62]. Under normal circumstances, dopamine is released only in response to specific stimuli, especially those previously related to a reward. As a result, those stimuli become extraordinary salient and attention grabbing for the individual. In contrast, as proposed by Kapur [62], dopamine release in schizophrenia patients might be stimulus-independent. It does not seem to be related to the patient's previous experiences with that stimulus and is not driven by the context, in which the stimuli are presented. Thus, dopamine artificially creates motivational salience, instead of mediating it. Hallucinations are assumed to be the primary manifests of that aberrant assignment of motivational salience, whereas delusions might be the secondary consequence of it, helping the patient to make sense of their impressions. So delusions provide the patients with "top-down" cognitive explanation of their experiences [62].

Despite the striking evidence of a hyperactive striatal dopamine system, previous studies often failed to show an elevated VTA response in schizophrenia patients. Actually, some studies report a hypoactivition of the VTA instead [63]-[65]. Only a few studies show a hyperactivation of the VTA [66]-[69]. Critically, none of them directly addressed salience processing.

There are several possible explanations for the reported diverging findings. First, medication might play a role. Antipsychotic drugs have shown to influence the dopaminergic system and thus might change VTA neuron activity. As all of the patients were medicated, this might be a possible confound in our data. But among both kinds of studies, those reporting hyperactivation and those reporting hypoactivation of the VTA, there are studies with and without the use of medication. According to that, it appears to be implausible, that medication is the only reason for the conflicting results. More plausible is it that the experimental task might be responsible for that variation, since different experimental conditions address different systems of the brain interacting with the dopamine system in variable ways. In our case, VTA hyperactivity might be linked to the hyperactivation of the fronto-parietal salience sensitive network or of parts of it.

One limitation of the present study is the possible coincidence of attentional bottom-up and top-down processes. As a consequence, both hyperactive top-down attentional control processes as compensatory mechanisms and hyperactive stimulus driven bottom-up processes of attention could be reflected by the results. But there is evidence that fast bottom-up selection occurs first in parietal areas, whereas longer-latency top-down selection relies primarily on frontal areas [70]. Activations of frontal areas obtained in the incongruency condition might therefore reflect a compensatory mechanism of schizophrenia patients to overcome the elevated salience signal. This dissociation of the task should be specifically addressed in a prospective study. 
Another limitation is that the diagnoses were not systematically derived based on semi-structural interviews. Nevertheless, accuracy of diagnoses was assured by consenting within members of the study group and the treating clinical psychiatrist.

\section{Conclusion}

In conclusion, the results of the present study are in favor of the predominant view of psychosis as a state of aberrant salience. The hyperactivation of the VTA, as part of the mesolimbic dopamine system, and the intraparietal cortex, as part of the reorienting network associated with the detection of potentially relevant information, which was previously shown to be sensitive to perceptive salience, links the finding of a hyperdopaminergic state of schizophrenic patients to their aberrant assignment of salience to only potentially relevant stimuli.

\section{Acknowledgements}

This work was partially funded by the Deutsche Forschungsgemeinschaft (DFG) via the Clinical Research Group 241 "Genotype-phenotype relationships and neurobiology of the longitudinal course of psychosis", TP 2 (http://www.kfo241.de; grant number GR 1950/5-1) and by a further DFG grant to Oliver Gruber (GR 1950/ 8-1).

\section{Conflict of Interest}

Oliver Gruber was honorary speaker for the following companies: Astra Zeneca, Bristol Myers Squibb, Janssen Cilag, Lilly, Servier, and Otsuka. He has been invited to scientific congresses by Astra Zeneca, Janssen Cilag and Pfizer and has received a research grant from Servier. All other authors declare that they have no conflicts of interest.

\section{References}

[1] Braff, D.L. (1993) Information Processing and Attention Dysfunctions in Schizophrenia. Schizophrenia Bulletin, 19, 233-259. http://dx.doi.org/10.1093/schbul/19.2.233

[2] Danckert, J., Saoud, M. and Maruff, P. (2004) Attention, Motor Control and Motor Imagery in Schizophrenia: Implications for the Role of the Parietal Cortex. Schizophrenia Research, 70, 241-261. http://dx.doi.org/10.1016/j.schres.2003.12.007

[3] Feldon, J. and Weiner, I. (1992) From an Animal Model of an Attentional Deficit towards New Insights into the Pathophysiology of Schizophrenia. Journal of Psychiatric Research, 26, 345-366. http://dx.doi.org/10.1016/0022-3956(92)90040-U

[4] Luck, S.J. and Gold, J.M. (2008) The Construct of Attention in Schizophrenia. Biological Psychiatry, 64, 34-39. http://dx.doi.org/10.1016/j.biopsych.2008.02.014

[5] McGhie, A. (1970) Attention and Perception in Schizophrenia. Progress in Experimental Personality Research, 5, $1-35$.

[6] Neale, J.M. and Cromwell, R.L. (1970) Attention and Schizophrenia. Progress in Experimental Personality Research, 5, 37-66.

[7] Nuechterlein, K.H. (1977) Reaction Time and Attention in Schizophrenia: A Critical Evaluation of the Data and Theories. Schizophrenia Bulletin, 3, 373-428. http://dx.doi.org/10.1093/schbul/3.3.373

[8] Nuechterlein, K.H., Pashler, H.E. and Subotnik, K.L. (2006) Translating Basic Attentional Paradigms to Schizophrenia Research: Reconsidering the Nature of the Deficits. Development and Psychopathology, 18, 831-851. http://dx.doi.org/10.1017/S095457940606041X

[9] Donohoe, G. and Robertson, I.H. (2003) Can Specific Deficits in Executive Functioning Explain the Negative Symptoms of Schizophrenia? A Review. Neurocase, 9, 97-108. http://dx.doi.org/10.1076/neur.9.2.97.15075

[10] Eisenberg, D.P. and Berman, K.F. (2010) Executive Function, Neural Circuitry, and Genetic Mechanisms in Schizophrenia. Neuropsychopharmacology: Official Publication of the American College of Neuropsychopharmacology, 35, 258-277. http://dx.doi.org/10.1038/npp.2009.111

[11] Freedman, D. and Brown, A.S. (2011) The Developmental Course of Executive Functioning in Schizophrenia. International Journal of Developmental Neuroscience: The Official Journal of the International Society for Developmental Neuroscience, 29, 237-243. http://dx.doi.org/10.1016/j.ijdevneu.2010.11.003 
[12] Kerns, J.G., Nuechterlein, K.H., Braver, T.S. and Barch, D.M (2008) Executive Functioning Component Mechanisms and Schizophrenia. Biological Psychiatry, 64, 26-33. http://dx.doi.org/10.1016/j.biopsych.2008.04.027

[13] Reuter, B. and Kathmann, N. (2004) Using Saccade Tasks as a Tool to Analyze Executive Dysfunctions in Schizophrenia. Acta Psychologica, 115, 255-269. http://dx.doi.org/10.1016/j.actpsy.2003.12.009

[14] Velligan, D.I. and Bow-Thomas, C.C. (1999) Executive Function in Schizophrenia. Seminars in Clinical Neuropsychiatry, 4, 24-33.

[15] Stroop, J.R. (1935) Studies of Interference in Serial Verbal Reactions. Journal of Experimental Psychology, 18, 643. http://dx.doi.org/10.1037/h0054651

[16] Henik, A. and Salo, R. (2004) Schizophrenia and the Stroop Effect. Behavioral and Cognitive Neuroscience Reviews, 3, 42-59. http://dx.doi.org/10.1177/1534582304263252

[17] Westerhausen, R., Kompus, K. and Hugdahl, K. (2011) Impaired Cognitive Inhibition in Schizophrenia: A MetaAnalysis of the Stroop Interference Effect. Schizophrenia Research, 133, 172-181. http://dx.doi.org/10.1016/j.schres.2011.08.025

[18] Botvinick, M.M., Braver, T.S., Barch, D.M., Carter, C.S. and Cohen, J.D. (2001) Conflict Monitoring and Cognitive Control. Psychological Review, 108, 624-652. http://dx.doi.org/10.1037/0033-295X.108.3.624

[19] Durston, S., Davidson, M.C., Thomas, K.M., Worden, M.S., Tottenham, N., et al. (2003) Parametric Manipulation of Conflict and Response Competition Using Rapid Mixed-Trial Event-Related fMRI. NeuroImage, 20, 2135-2141. http://dx.doi.org/10.1016/j.neuroimage.2003.08.004

[20] Fan, J., Flombaum, J.I., McCandliss, B.D., Thomas, K.M. and Posner, M.I. (2003) Cognitive and Brain Consequences of Conflict. NeuroImage, 18, 42-57. http://dx.doi.org/10.1006/nimg.2002.1319

[21] Milham, M.P., Banich, M.T. and Barad, V. (2003) Competition for Priority in Processing Increases Prefrontal Cortex's Involvement in Top-Down Control: An Event-Related fMRI Study of the Stroop Task. Cognitive Brain Research, 17, 212-222. http://dx.doi.org/10.1016/S0926-6410(03)00108-3

[22] Milham, M.P. and Banich, M.T. (2005) Anterior Cingulate Cortex: An fMRI Analysis of Conflict Specificity and Functional Differentiation. Human Brain Mapping, 25, 328-335. http://dx.doi.org/10.1002/hbm.20110

[23] Roelofs, A. (2003) Goal-Referenced Selection of Verbal Action: Modeling Attentional Control in the Stroop Task. Psychological Review, 110, 88-125. http://dx.doi.org/10.1037/0033-295X.110.1.88

[24] Ullsperger, M. and von Cramon, D.Y. (2001) Subprocesses of Performance Monitoring: A Dissociation of Error Processing and Response Competition Revealed by Event-Related fMRI and ERPs. NeuroImage, 14, 1387-1401. http://dx.doi.org/10.1006/nimg.2001.0935

[25] Van Veen, V. and Carter, C.S. (2005) Separating Semantic Conflict and Response Conflict in the Stroop Task: A Functional MRI Study. NeuroImage, 27, 497-504. http://dx.doi.org/10.1016/j.neuroimage.2005.04.042

[26] Zysset, S., Müller, K., Lohmann, G. and von Cramon, D.Y. (2001) Color-Word Matching Stroop Task: Separating Interference and Response Conflict. NeuroImage, 13, 29-36. http://dx.doi.org/10.1006/nimg.2000.0665

[27] Bledowski, C., Prvulovic, D., Goebel, R., Zanella, F.E. and Linden, D.E.J. (2004) Attentional Systems in Target and Distractor Processing: A Combined ERP and fMRI Study. NeuroImage, 22, 530-540. http://dx.doi.org/10.1016/j.neuroimage.2003.12.034

[28] Huettel, S.A., Mack, P.B. and McCarthy, G. (2002) Perceiving Patterns in Random Series: Dynamic Processing of Sequence in Prefrontal Cortex. Nature Neuroscience, 5, 485-490. http://dx.doi.org/10.1038/nn841

[29] Gruber, O., Melcher, T., Diekhof, E.K., Karch, S., Falkai, P. and Goschke, T. (2009) Brain Mechanisms Associated with Background Monitoring of the Environment for Potentially Significant Sensory Events. Brain and Cognition, 69, 559-564. http://dx.doi.org/10.1016/j.bandc.2008.11.008

[30] Gruber, O., Diekhof, E.K., Kirchenbauer, L. and Goschke, T. (2010) A Neural System for Evaluating the Behavioural Relevance of Salient Events outside the Current Focus of Attention. Brain Research, 1351, 212-221. http://dx.doi.org/10.1016/j.brainres.2010.06.056

[31] Melcher, T., Wolter, S., Falck, S., Wild, E., Wild, F., et al. (2013) Common and Disease-Specific Dysfunctions of Brain Systems Underlying Attentional and Executive Control in Schizophrenia and Bipolar Disorder. European Archives of Psychiatry and Clinical Neuroscience, 264, 517-532. http://dx.doi.org/10.1007/s00406-013-0445-9

[32] Melcher, T. and Gruber, O. (2006) Oddball and Incongruity Effects during Stroop Task Performance: A Comparative fMRI Study on Selective Attention. Brain Research, 1121, 136-149. http://dx.doi.org/10.1016/j.brainres.2006.08.120

[33] Brett, M., Anton, J.-L., Valabregue, R. and Poline, J.-B. (2002) Region of Interest Analysis Using the MarsBar Toolbox for SPM 99. NeuroImage, 16, 497.

[34] Donner, T., Kettermann, A., Diesch, E., Ostendorf, F., Villringer, A. and Brandt, S.A. (2000) Involvement of the Human Frontal Eye Field and Multiple Parietal Areas in Covert Visual Selection during Conjunction Search. European 
Journal of Neuroscience, 12, 3407-3414. http://dx.doi.org/10.1046/j.1460-9568.2000.00223.x

[35] Goebel, R., Linden, D.E., Lanfermann, H., Zanella, F.E. and Singer, W. (1998) Functional Imaging of Mirror and Inverse Reading Reveals Separate Coactivated Networks for Oculomotion and Spatial Transformations. Neuroreport, 9, 713-719. http://dx.doi.org/10.1097/00001756-199803090-00028

[36] Schall, J.D. (2002) The Neural Selection and Control of Saccades by the Frontal Eye Field. Philosophical Transactions of the Royal Society of London. Series B: Biological Sciences, 357, 1073-1082. http://dx.doi.org/10.1098/rstb.2002.1098

[37] Wojciulik, E. and Kanwisher, N. (1999) The Generality of Parietal Involvement in Visual Attention. Neuron, 23, 747764. http://dx.doi.org/10.1016/S0896-6273(01)80033-7

[38] Geng, J.J. and Mangun, G.R. (2008) Anterior Intraparietal Sulcus Is Sensitive to Bottom-Up Attention Driven by Stimulus Salience. Journal of Cognitive Neuroscience, 21, 1584-1601. http://dx.doi.org/10.1162/jocn.2009.21103

[39] Calhoun, V.D., Wu, L., Kiehl, K.A., Eichele, T. and Pearlson, G.D. (2010) Aberrant Processing of Deviant Stimuli in Schizophrenia Revealed by Fusion of fMRI and EEG Data. Acta Neuropsychiatrica, 22, 127-138. http://dx.doi.org/10.1111/j.1601-5215.2010.00467.x

[40] Gur, R. (2007) Visual Attention Circuitry in Schizophrenia Investigated with Oddball Event-Related Functional Magnetic Resonance Imaging. American Journal of Psychiatry, 164, 442-449. http://dx.doi.org/10.1176/ajp.2007.164.3.442

[41] Kiehl, K.A. and Liddle, P.F. (2001) An Event-Related Functional Magnetic Resonance Imaging Study of an Auditory Oddball Task in Schizophrenia. Schizophrenia Research, 48, 159-171. http://dx.doi.org/10.1016/S0920-9964(00)00117-1

[42] Laurens, K.R., Kiehl, K.A., Ngan, E.T.C. and Liddle, P.F. (2005) Attention Orienting Dysfunction during Salient Novel Stimulus Processing in Schizophrenia. Schizophrenia Research, 75, 159-171. http://dx.doi.org/10.1016/j.schres.2004.12.010

[43] Liddle, P.F., Laurens, K.R., Kiehl, K.A. and Ngan, E.T.C. (2006) Abnormal Function of the Brain System Supporting Motivated Attention in Medicated Patients with Schizophrenia: An fMRI Study. Psychological Medicine, 36, 10971108. http://dx.doi.org/10.1017/S0033291706007677

[44] Ngan, E.T.C., Vouloumanos, A., Cairo, T.A., Laurens, K.R., Bates, A.T., Anderson, C.M., Werker, J.F. and Liddle, P.F. (2003) Abnormal Processing of Speech during Oddball Target Detection in Schizophrenia. NeuroImage, 20, 889897. http://dx.doi.org/10.1016/S1053-8119(03)00385-9

[45] Wolf, D.H., Turetsky, B.I., Loughead, J., Elliott, M.A., Pratiwadi, R., Gur, R.E. and Gur, R.C. (2008) Auditory Oddball fMRI in Schizophrenia: Association of Negative Symptoms with Regional Hypoactivation to Novel Distractors. Brain Imaging and Behavior, 2, 132-145. http://dx.doi.org/10.1007/s11682-008-9022-7

[46] Choi, J.W., Jeong, B.S. and Kim, J.-W. (2008) Dysfunction of the Left Dorsolateral Prefrontal Cortex Is Primarily Responsible for Impaired Attentional Processing in Schizophrenia. Psychiatry Investigation, 5, 52-59. http://dx.doi.org/10.4306/pi.2008.5.1.52

[47] Kerns, J.G., Cohen, J.D., MacDonald, I., Angus, W., Johnson, M.K., Stenger, V.A., Aizenstein, H. and Carter, C.S. (2005) Decreased Conflict- and Error-Related Activity in the Anterior Cingulate Cortex in Subjects with Schizophrenia. American Journal of Psychiatry, 162, 1833-1839. http://dx.doi.org/10.1176/appi.ajp.162.10.1833

[48] Park, I.H., Park, H.-J., Chun, J.-W., Kim, E.Y. and Kim, J.-J. (2008) Dysfunctional Modulation of Emotional Interference in the Medial Prefrontal Cortex in Patients with Schizophrenia. Neuroscience Letters, 440, 119-124. http://dx.doi.org/10.1016/j.neulet.2008.05.094

[49] Reid, M.A., Stoeckel, L.E., White, D.M., Avsar, K.B., Bolding, M.S., et al. (2010) Assessments of Function and Biochemistry of the Anterior Cingulate Cortex in Schizophrenia. Biological Psychiatry, 68, 625-633. http://dx.doi.org/10.1016/j.biopsych.2010.04.013

[50] Ungar, L., Nestor, P.G., Niznikiewicz, M.A., Wible, C.G. and Kubicki, M. (2010) Color Stroop and Negative Priming in Schizophrenia: An fMRI Study. Psychiatry Research: Neuroimaging, 181, 24-29. http://dx.doi.org/10.1016/j.pscychresns.2009.07.005

[51] Weiss, E.M., Siedentopf, C., Golaszewski, S., Mottaghy, F.M., Hofer, A., et al. (2007) Brain Activation Patterns during a Selective Attention Test-A Functional MRI Study in Healthy Volunteers and Unmedicated Patients during an Acute Episode of Schizophrenia. Psychiatry Research: Neuroimaging, 154, 31-40. http://dx.doi.org/10.1016/j.pscychresns.2006.04.009

[52] Cavezian, C., Striemer, C., Saoud, M., Rossetti, Y. and Danckert, J. (2006) Schizophrenia and the Neglect Syndrome: Parietal Contributions to Cognitive Dysfunction in Schizophrenia. Current Psychiatry Reviews, 2, 439-451. http://dx.doi.org/10.2174/157340006778699701

[53] Bender, M.B. (1952) Disorders in Perception: With Particular Reference to the Phenomena of Extinction and Dis- 
placement. Vol. 8, Charles C Thomas Publisher, Springfield. http://dx.doi.org/10.1037/13218-000

[54] Molenberghs, P., Gillebert, C.R., Peeters, R. and Vandenberghe, R. (2008) Convergence between Lesion-Symptom Mapping and Functional Magnetic Resonance Imaging of Spatially Selective Attention in the Intact Brain. The Journal of Neuroscience, 28, 3359-3373. http://dx.doi.org/10.1523/JNEUROSCI.5247-07.2008

[55] Vandenberghe, R. and Gillebert, C.R. (2009) Parcellation of Parietal Cortex: Convergence between Lesion-Symptom Mapping and Mapping of the Intact Functioning Brain. Behavioural Brain Research, 199, 171-182. http://dx.doi.org/10.1016/j.bbr.2008.12.005

[56] Bichot, N.P. and Schall, J.D. (1999) Effects of Similarity and History on Neural Mechanisms of Visual Selection. Nature Neuroscience, 2, 549-554. http://dx.doi.org/10.1038/9205

[57] Van Rossum, J.M. (1966) The Significance of Dopamine-Receptor Blockade for the Mechanism of Action of Neuroleptic Drugs. Archives Internationales de Pharmacodynamie et de Thérapie, 160, 492-494.

[58] Davis, K.L., Kahn, R.S., Ko, G. and Davidson, M. (1991) Dopamine in Schizophrenia: A Review and Reconceptualization. The American Journal of Psychiatry, 148, 1474-1486. http://dx.doi.org/10.1176/ajp.148.11.1474

[59] Haber, S.N. and Knutson, B. (2009) The Reward Circuit: Linking Primate Anatomy and Human Imaging. Neuropsychopharmacology, 35, 4-26. http://dx.doi.org/10.1038/npp.2009.129

[60] Sesack, S.R. and Grace, A.A. (2009) Cortico-Basal Ganglia Reward Network: Microcircuitry. Neuropsychopharmacology, 35, 27-47. http://dx.doi.org/10.1038/npp.2009.93

[61] Howes, O.D. and Kapur, S. (2009) The Dopamine Hypothesis of Schizophrenia: Version III-The Final Common Pathway. Schizophrenia Bulletin, 35, 549-562. http://dx.doi.org/10.1093/schbul/sbp006

[62] Kapur, S. (2003) Psychosis as a State of Aberrant Salience: A Framework Linking Biology, Phenomenology, and Pharmacology in Schizophrenia. The American Journal of Psychiatry, 160, 13-23. http://dx.doi.org/10.1176/appi.ajp.160.1.13

[63] Gradin, V.B., Kumar, P., Waiter, G., Ahearn, T., et al. (2011) Expected Value and Prediction Error Abnormalities in Depression and Schizophrenia. Brain, 134, 1751-1764. http://dx.doi.org/10.1093/brain/awr059

[64] Takahashi, H., Koeda, M., Oda, K., Matsuda, T., Matsushima, E., et al. (2004) An fMRI Study of Differential Neural Response to Affective Pictures in Schizophrenia. NeuroImage, 22, 1247-1254. http://dx.doi.org/10.1016/j.neuroimage.2004.03.028

[65] Waltz, J.A., Schweitzer, J.B., Gold, J.M., Kurup, P.K., Ross, T.J., et al. (2008) Patients with Schizophrenia Have a Reduced Neural Response to Both Unpredictable and Predictable Primary Reinforcers. Neuropsychopharmacology, 34, 1567-1577. http://dx.doi.org/10.1038/npp.2008.214

[66] Fahim, C., Stip, E., Mancini-Marie, A., Gendron, A., Mensour, B. and Beauregard, M. (2005) Differential Hemodynamic Brain Activity in Schizophrenia Patients with Blunted Affect during Quetiapine Treatment. Journal of Clinical Psychopharmacology, 25, 367-371. http://dx.doi.org/10.1097/01.jcp.0000168880.10793.ed

[67] Fahim, C., Stip, E., Mancini-Marïe, A., Mensour, B., Boulay, L.J., et al. (2005) Brain Activity during Emotionally Negative Pictures in Schizophrenia with and without Flat Affect: An fMRI Study. Psychiatry Research: Neuroimaging, 140, 1-15. http://dx.doi.org/10.1016/j.pscychresns.2005.06.003

[68] Romaniuk, L., Honey, G.D., King, J.L., et al. (2010) Midbrain Activation during Pavlovian Conditioning and Delusional Symptoms in Schizophrenia. Archives of General Psychiatry, 67, 1246-1254. http://dx.doi.org/10.1001/archgenpsychiatry.2010.169

[69] Yoon, J.H., Minzenberg, M.J., Raouf, S., D’Esposito, M. and Carter, C.S. (2013) Impaired Prefrontal-Basal Ganglia Functional Connectivity and Substantia Nigra Hyperactivity in Schizophrenia. Biological Psychiatry, 74, 122-129. http://dx.doi.org/10.1016/j.biopsych.2012.11.018

[70] Buschman, T.J. and Miller, E.K. (2007) Top-Down versus Bottom-Up Control of Attention in the Prefrontal and Posterior Parietal Cortices. Science, 315, 1860-1862. http://dx.doi.org/10.1126/science.1138071 


\section{Submit or recommend next manuscript to SCIRP and we will provide best service for you:}

Accepting pre-submission inquiries through Email, Facebook, LinkedIn, Twitter, etc.

A wide selection of journals (inclusive of 9 subjects, more than 200 journals)

Providing 24-hour high-quality service

User-friendly online submission system

Fair and swift peer-review system

Efficient typesetting and proofreading procedure

Display of the result of downloads and visits, as well as the number of cited articles

Maximum dissemination of your research work

Submit your manuscript at: http://papersubmission.scirp.org/ 